\title{
Perbandingan Gabapentin 600 mg dengan Pregabalin 150 mg Preoperatif terhadap Nilai Numeric Rating Scale dan Pengurangan Kebutuhan Opioid Pascaoperasi Modifikasi Radikal Mastektomi
}

\author{
Rully Agustine, ${ }^{1}$ Ezra Oktaliansah, ${ }^{2}$ Eri Surahman ${ }^{2}$ \\ ${ }^{1}$ Bagian Anestesi Rumah Sakit Hermina Sukabumi, ${ }^{2}$ Departemen Anestesiologi dan Terapi intensif \\ Fakultas Kedokteran Universitas Padjadjaran/Rumah Sakit Dr. Hasan Sadikin Bandung
}

\begin{abstract}
Abstrak
Gabapentin dan pregabalin mempunyai efek antihiperalgesia, antialodinia, dan antinosiseptif untuk mengurangi nyeri pascaoperatif. Penelitian ini bertujuan untuk membandingkan gabapentin $600 \mathrm{mg}$ $(\mathrm{n}=22)$ dengan pregabalin $150 \mathrm{mg}(22)$ terhadap nyeri pascaoperatif modifikasi mastektomi radikal, yang dilakukan terhadap 44 wanita (18-65 tahun) status fisik American Society of Anesthesiologist (ASA) I-II secara uji acak terkontrol buta ganda dalam anestesi umum di Rumah Sakit Dr. Hasan Sadikin Bandung pada November 2011 sampai Maret 2012. Analisis statistik menggunakan Uji Mann-Whitney, uji-t, dan uji chikuadrat dengan tingkat kepercayaan 95\% dan bermakna bila $p<0,05$. Penilaian skala nyeri menggunakan nilai numeric rating scale (NRS). Nilai NRS saat berbaring pada kelompok gabapentin $600 \mathrm{mg}$ dan pregabalin $150 \mathrm{mg}$ adalah sama $(\mathrm{p}>0,05)$. Nilai NRS saat mobilisasi pregabalin $150 \mathrm{mg}$ lebih baik daripada gabapentin $600 \mathrm{mg}$ pada tujuh dari sepuluh waktu pengukuran $(\mathrm{p}<0,05)$. Pemberian analgetik tambahan pascaoperatif antara kedua kelompok adalah sama ( $>0,05)$. Simpulan, pregabalin $150 \mathrm{mg}$ preoperatif lebih baik daripada gabapentin $600 \mathrm{mg}$ dalam menurunkan nilai NRS pascaoperasi. Gabapentin $600 \mathrm{mg}$ dan pregabalin $150 \mathrm{mg}$ mampu menurunkan kebutuhan opioid pascaoperatif.
\end{abstract}

Kata kunci: Gabapentin, kebutuhan analgetik opioid, numeric rating scale, nyeri pascaoperatif, pregabalin

\section{Comparison of Numeric Rating Scale Value and Post operative Opioid Requirement after Modified Radical Mastectomy between the Use of Pre-operative $600 \mathrm{mg}$ Gabapentin and $150 \mathrm{mg}$ Pregabalin Use}

\begin{abstract}
Gabapentin and pregabalin has anti hyperalgesia, anti allodynia, and anti nociceptive effects which lead to their use as additional medications to reduce post operative pain. This study compared the use of $600 \mathrm{mg}$ gabapentin and $150 \mathrm{mg}$ pregabalin in managing post-operative pain following modified radical mastectomy. The study was performed by conducting a double blind randomized controlled trial on 44 patients, aged 18-65 years old with American Society of Anesthesiologist (ASA) physical status I-II, who underwent modified radical mastectomy operation under general anesthesia, at Dr. Hasan Sadikin General Hospital Bandung during the period of November 2011 to March 2012. Patients were divided into two groups, 600 mg gabapentin $(n=22)$, and $150 \mathrm{mg}$ pregabalin $(\mathrm{n}=22)$ groups. The statistical analysis was conducted using Mann-Whitney Test, t-test, and chi-square test with 95\% confidence interval. The results of the analysis would be considered significant if $p<0.05$. The quality of pain was assessed using the numeric rating scale. The NRS value at rest was similar in both groups ( $p>0.05$ ). NRS during mobilization were significantly different in nine measurements $(\mathrm{p}<0.05)$. Total post-operative additional analgesia showed no significant difference in both groups ( $p>0.05$ ). Therefore, oral preoperative $150 \mathrm{mg}$ pregabalin is better than $600 \mathrm{mg}$ gabapentin for reducing post-operative NRS. In addition, $600 \mathrm{mg}$ Gabapentin and $150 \mathrm{mg}$ pregabalin also reduce post-operative opioid consumption.
\end{abstract}

Key words: Gabapentin, numeric rating scale score, opioid analgesic requirement, post operative, pregabalin

Korespondensi: Rully Agustine, dr., SpAn, Bagian Anestesi Rumah Sakit Hermina Sukabumi, Jl. Sukaraja Sukabumi, Mobile 081361471122, Email rullyagustine@yahoo.com 


\section{Pendahuluan}

Sindrom nyeri pascaoperatif pada mastektomi mempunyai insidensi yang cukup tinggi, yaitu 20-50\%. Sindrom ini merupakan nyeri kronik persisten yang terjadi pascaoperasi. Sindrom ini dapat dicegah melalui tindakan penanganan nyeri pascaoperatif yang lebih baik. ${ }^{1}$ Konsep terkini dengan metode analgesia multimodal pascaoperatif didasarkan pada penggunaan opioid yang dikombinasikan dengan obat jenis lain, antara lain nonsteroidal antiinflamatory drugs (NSAID) atau parasetamol, atau ketamin dosis rendah, serta pemberian anestetik lokal perioperatif.

Analgetik yang termasuk golongan NSAID cyclooxygenase-1 berhubungan dengan efek samping kerusakan dan perdarahan mukosa gastrointestinal, toksik terhadap ginjal, serta reaksi alergi. Obat NSAID golongan selektif terhadap cyclooxygenase-2 mempunyai efek protrombotik dapat meningkatkan risiko strok dan iskemia miokardium. Penggunaan ketamin dapat menimbulkan efek psikotogenik. Obat analgesia yang baik adalah yang mempunyai efek meningkatkan kualitas analgesia opioid, toleransi baik terhadap opioid, mengurangi ansietas, dan juga tidak ada efek samping yang dimiliki oleh obat analgesi yang lain, mungkin dapat menjadi adjuvan analgesia perioperatif. ${ }^{2}$

Obat dengan karakteristik seperti di atas antara lain adalah golongan gabapentinoid seperti gabapentin dan pregabalin. Kedua obat ini adalah obat yang sering digunakan sebagai antikonvulsan yang kemudian diketahui dapat digunakan untuk penatalaksanan nyeri akut pascaoperatif dan nyeri kronik. ${ }^{3}$

Gabapentin diperkenalkan sebagai obat antiepilepsi pada tahun 1993, yang merupakan analog struktur gamma amino butyric acid (GABA) yang mempunyai efek anti allodynia, antihiperalgesia, serta antinosiseptif sehingga dapat dipergunakan sebagai salah satu pilihan untuk penatalaksanaan nyeri pascaoperatif. ${ }^{2}$ Penelitian mengenai penggunaan gabapentin dosis tunggal preoperatif dalam berbagai dosis (300 mg, $600 \mathrm{mg}$, $900 \mathrm{mg}$, dan $1.200 \mathrm{mg}$ ) telah dilakukan pada pembedahan diseksi lumbal. Hasil akhir penelitian tersebut didapatkan nilai analgesic ceiling pada dosis $600 \mathrm{mg}$, artinya, reduksi nyeri pada dosis $600 \mathrm{mg}$ lebih baik dibandingkan dengan dosis 300 mg tetapi tidak ada efek yang menguntungkan bila dosis dinaikan menjadi $900 \mathrm{mg}$ atau $1.200 \mathrm{mg}$, maka dosis yang dipergunakan pada penelitian ini adalah $600 \mathrm{mg}^{4}{ }^{4}$

Pregabalin juga merupakan suatu analog struktur gamma amino butyric acid (GABA) yang mempunyai beberapa karakteristik yang sama dengan gabapentin, namun mempunyai profil farmakokinetik yang lebih superior serta lebih poten dibandingkan dengan gabapentin, sehingga dosis yang digunakan lebih rendah. ${ }^{5}$ Dosis pregabalin 2-4 kali lebih kecil apabila dibandingkan dengan gabapentin dan efektif dipakai untuk nyeri neuropatik, ${ }^{6}$ yaitu pada dosis $150 \mathrm{mg}$. Penelitian ini bertujuan untuk membandingkan numeric rating scale serta jumlah kebutuhan opioid pascaoperatif antara gabapentin $600 \mathrm{~g}$ dan pregabalin $150 \mathrm{~g}$.

\section{Subjek dan Metode}

Metode penelitian yang dipergunakan adalah eksperimental dengan uji acak terkontrol buta ganda. Pemilihan subjek penelitian ini adalah berdasarkan kriteria inklusi, yaitu status fisik pasien American Society of Anesthesiologist (ASA) I-II, berusia 18-65 tahun yang dirawat di Rumah Sakit Dr. Hasan Sadikin Bandung, yang akan menjalani operasi modifikasi radikal mastektomi elektif dengan anestesia umum. Kriteria eksklusi, yaitu terdapat kontraindikasi pemberian obat yang dipakai pada penelitian, sedang mendapatkan pengobatan analgetik (seperti opioid, tramadol, parasetamol, NSAID), atau antiepileptik. Penelitian dilakukan pada periode November 2011 sampai dengan Maret 2012. Besarnya sampel dihitung berdasarkan rumus uji hipotesis dua rata-rata sehingga didapatkan jumlah sampel 22 orang untuk tiap kelompok perlakuan.

Analisis statistika penelitian menggunakan uji-t, chi-kuadrat, dan juga Uji Mann-Whitney. Data ditampilkan dalam rata-rata (mean) yang dianalisis dengan mempergunakan program statistical product and servise solution (SPSS) 11,0 for windows. 
Semua kelompok perlakuan mendapatkan pemberian premedikasi dengan lorazepam 0,5 mg pada malam hari. Dua jam sebelum induksi, pasien kelompok gabapentin (GB) diberikan gabapentin $600 \mathrm{mg}$, sedangkan pada kelompok pregabalin (PG) diberikan pregabalin $150 \mathrm{mg}$. Saat di ruang operasi dilakukan pemasangan kateter infus intravena ukuran $18 \mathrm{G}$ kemudian diberikan cairan infus Ringer laktat $10 \mathrm{~mL} /$ kgBB untuk menggantikan puasa.

Induksi dimulai dengan memakai propofol $2 \mathrm{mg} / \mathrm{kgBB}$, fentanil $2 \mu \mathrm{g} / \mathrm{kgBB}$, atrakurium $0,5 \mathrm{mg} / \mathrm{kgBB}$, dan juga deksametason $0,2 \mathrm{mg} /$ $\mathrm{kgBB}$. Setelah 3 menit dilakukan laringoskopiintubasi. Pemeliharaan anestesia dilakukan dengan mempergunakan enfluran 2 vol\% serta $\mathrm{N}_{2} \mathrm{O}: \mathrm{O}_{2} 50 \%$. Pada saat akhir operasi diberikan antagonis pelumpuh otot dengan neostigmin $0,03 \mathrm{mg} / \mathrm{kgBB}$ dan juga sulfas atropin 0,01 $\mathrm{mg} / \mathrm{kgBB}$. Pencegahan mual muntah diberikan ondansetron $0,05 \mathrm{mg} / \mathrm{kgBB}$ secara intravena. Untuk analgetik pascaoperatif diberikan infus kontinu petidin memakai infus pump $(0,3 \mathrm{mg} /$ $\mathrm{kgBB} / \mathrm{jam}$ ).

Penilaian nyeri pascaoperasi menggunakan numeric rating scale (NRS) pada saat masuk ke ruang pemulihan (jam ke-0), 1, 2, 3, dan 4 jam pertama, kemudian saat $8,12,20$, serta 24 jam. Pencatatan NRS, laju nadi, tekanan darah, $\mathrm{SpO}_{2}$, laju napas, efek samping, penggunaan petidin tambahan, serta jumlah penggunaan petidin dilakukan selama 24 jam. Bila nilai NRS lebih dari 3 diberikan analgetik penyelamatan menggunakan petidin $25 \mathrm{mg}$. Bila nilai NRS masih lebih dari 3, maka 15 menit kemudian diberikan analgetik pertolongan ulangan.

\section{Hasil}

Hasil analisis statistika menunjukkan bahwa untuk karakteristik usia, berat badan, tinggi badan, body mass index (BMI), durasi operasi, dan pendidikan pada kedua kelompok secara statistika didapatkan hasil yang tidak berbeda signifikan $(p>0,05)$, sehingga seluruh subjek yang diteliti adalah homogen dan layak untuk dibandingkan (Tabel 1).

Karakteristik tekanan darah sistol, diastol, tekanan rata-rata arteri, laju nadi, laju napas, dan juga saturasi oksigen tidak didapatkan perbedaan yang bermakna antara kelompok gabapentin $600 \mathrm{mg}$ dan pregabalin $150 \mathrm{mg}$

Tabel 1 Karakteristik Umum Subjek Penelitian Kelompok Gabapentin 600 mg dan Pregabalin $150 \mathrm{mg}$

\begin{tabular}{|c|c|c|c|}
\hline \multirow{2}{*}{ Karakteristik } & \multicolumn{2}{|c|}{ Kelompok } & \multirow{2}{*}{ Nilai $p$} \\
\hline & $P G(n=22)$ & GB $(n=22)$ & \\
\hline \multicolumn{4}{|l|}{ Usia (tahun) } \\
\hline Rata-rata (SD) & $45,23(8,14)$ & $44,73(7,82)$ & 0,836 \\
\hline Rentang & $31-58$ & $31-63$ & \\
\hline \multicolumn{4}{|l|}{ Berat badan $(\mathrm{kg})$} \\
\hline Rata-rata (SD) & $57,7(9,4)$ & $52,3(5,6)$ & 0,775 \\
\hline Rentang & $48-66$ & $50-66$ & \\
\hline \multicolumn{4}{|l|}{$\operatorname{BMI}\left(\mathrm{kg} / \mathrm{m}^{2}\right)$} \\
\hline Rata-rata (SD) & $23,36(3,32)$ & $21,41(2,08)$ & 0,055 \\
\hline Rentang & $18-30$ & $18-28$ & \\
\hline \multicolumn{4}{|l|}{ Pendidikan } \\
\hline SD & 12 & 10 & 0,883 \\
\hline SMP & 6 & 6 & \\
\hline SMA & 3 & 4 & \\
\hline S1 & 1 & 2 & \\
\hline \multicolumn{4}{|l|}{ Lama operasi (menit) } \\
\hline Rata-rata (SD) & $132,95(27,3)$ & $137,95(30,8)$ & 0,392 \\
\hline Rentang & $90-180$ & $90-180$ & \\
\hline
\end{tabular}

Keterangan: nilai p pada variabel usia dihitung berdasarkan uji-t. Nilai p pada variabel berat badan, BMI dan lama operasi dihitung berdasarkan Uji Mann-Whitney. Nilai p pada variabel pendidikan dihitung berdasarkan uji chi-kuadrat. Nilai $p$ bermakna bila $\mathrm{p}<0,05$ 
Tabel 2 Perbandingan Tingkat Kecemasan antara Kelompok Gabapentin 600 mg dan Kelompok Pregabalin $150 \mathrm{mg}$

\begin{tabular}{lccc}
\hline \multirow{2}{*}{ Jenis Kecemasan } & \multicolumn{2}{c}{ Kelompok } & \multirow{2}{*}{ Nilai p } \\
\cline { 2 - 3 } & PG (n=22) & GB (n=22) & \\
\hline Ringan & 16 & 13 & 0,340 \\
Sedang & 6 & 9 & \\
\hline
\end{tabular}

Keterangan: nilai $p$ pada variabel pendidikan dihitung berdasarkan uji chi-kuadrat. Nilai p bermakna jika $p<0,05$

$(p>0,05)$, berarti subjek homogen dan layak untuk diperbandingkan (Gambar 1-6). Tingkat kecemasan kedua kelompok sebagian besar adalah kecemasan ringan dan tidak berbeda bermakna ( $p>0,05)$, sehingga subjek tersebut layak untuk diperbandingkan (Tabel 2).

Penilaian NRS pada saat diam menunjukkan tidak terdapat perbedaan yang bermakna pada nilai NRS saat diam (NRS 0) antara pemberian gabapentin $600 \mathrm{mg}$ dan pregabalin $150 \mathrm{mg}$ pada jam ke-0, 1, 2, 3, 4, 8, 12, 16, 20, dan 24 ( $p>0,05$; Tabel 3; Gambar 7; Gambar 8).

Penilaian NRS saat mobilisasi menunjukkan perbedaan yang signifikan antara pemberian gabapentin $600 \mathrm{mg}$ dan pregabalin $150 \mathrm{mg}$ pada pengukuran jam ke-1, 2, 3, 4, 8, 12, dan 20 ( $\mathrm{p}<0,05$; Tabel 4; Gambar 9; Gambar 10).
Pemakaian analgetik tambahan dilakukan pada 2 (dua) orang pada kelompok pregabalin (PG) dan 3 orang pada kelompok gabapentin (GB). Perbedaan jumlah pemakaian analgetik tambahan antara kedua kelompok tersebut tidak berbeda bermakna ( $p>0,05$; Tabel 5).

\section{Pembahasan}

Penilaian NRS pada saat diam (NRS 0) antara kelompok gabapentin $600 \mathrm{mg}$ dan pregabalin 150 mg mempunyai nilai $p>0,05$ pada 9 dari 10 waktu pengukuran, berarti tidak terdapat perbedaan bermakna antara nilai NRS saat diam antara kelompok gabapentin $600 \mathrm{mg}$ dan pregabalin $150 \mathrm{mg}$. Nilai NRS dari gabapentin $600 \mathrm{mg}$ dan pregabalin $150 \mathrm{mg}$ ini berkisar

Tabel 3 Perbandingan Nilai NRS Saat Diam (NRS 0) antara Kelompok Gabapentin 600 mg dan Pregabalin $150 \mathrm{mg}$

\begin{tabular}{|c|c|c|c|c|c|}
\hline \multirow{3}{*}{$\begin{array}{c}\text { Waktu } \\
\text { Pengukuran }\end{array}$} & \multicolumn{4}{|c|}{ Kelompok } & \multirow{3}{*}{ Nilai p } \\
\hline & \multicolumn{2}{|c|}{$P G(n=22)$} & \multicolumn{2}{|c|}{ GB $(n=22)$} & \\
\hline & Median & Rentang & Median & Rentang & \\
\hline $\mathrm{T}_{0}$ & 0 & $0-1$ & 0 & $0-1$ & 0,317 \\
\hline $\mathrm{T}_{1}$ & 0 & $0-1$ & 1 & $0-2$ & 0,299 \\
\hline $\mathrm{T}_{2}$ & 1 & $0-2$ & 1 & $0-2$ & 0,757 \\
\hline $\mathrm{T}_{3}$ & 1 & $0-2$ & 1 & $0-4$ & $0,014^{* *}$ \\
\hline $\mathrm{T}_{4}$ & 1 & $0-2$ & 1 & $0-3$ & 0,662 \\
\hline $\mathrm{T}_{8}$ & 1 & $0-2$ & 1 & $0-2$ & 0,242 \\
\hline $\mathrm{T}_{12}$ & 1 & $0-3$ & 1 & $0-3$ & 0,425 \\
\hline $\mathrm{T}_{16}$ & 1 & $0-3$ & 1 & $0-3$ & 0,152 \\
\hline $\mathrm{T}_{20}$ & 1 & $0-3$ & 1 & $0-3$ & 0,745 \\
\hline $\mathrm{T}_{24}$ & 1 & $0-2$ & 1,5 & $0-2$ & 0,618 \\
\hline
\end{tabular}

Keterangan: $\mathrm{T}_{0}=$ saat masuk RR, T1=jam ke-1, $\mathrm{T}_{2}=$ =jam ke-2, dan seterusnya. Nilai p dihitung berdasarkan Uji Mann Whitney. Nilai p bermakna bila $\mathrm{p}<0,05$ 
Tabel 4 Perbandingan Nilai NRS Mobilisasi (NRS 1) antara Kelompok Gabapentin 600 mg dan Pregabalin $150 \mathrm{mg}$

\begin{tabular}{|c|c|c|c|c|c|}
\hline \multirow{3}{*}{$\begin{array}{c}\text { Waktu } \\
\text { Pengukuran }\end{array}$} & \multicolumn{4}{|c|}{ Kelompok } & \multirow{3}{*}{ Nilai p } \\
\hline & \multicolumn{2}{|c|}{$P G(n=22)$} & \multicolumn{2}{|c|}{ GB $(n=22)$} & \\
\hline & Median & Rentang & Median & Rentang & \\
\hline $\mathrm{T}_{0}$ & 0 & $0-1$ & 0 & $0-2$ & 0,644 \\
\hline $\mathrm{T}_{1}$ & 0 & $0-1$ & 1 & $0-2$ & $0,034^{* *}$ \\
\hline $\mathrm{T}_{2}$ & 1 & $0-1$ & 1 & $0-2$ & $0,030^{\text {** }}$ \\
\hline $\mathrm{T}_{3}$ & 1 & $0-2$ & 1 & $0-3$ & $0,024^{* *}$ \\
\hline $\mathrm{T}_{4}$ & 1 & $0-3$ & 2 & $0-2$ & $0,003^{* *}$ \\
\hline $\mathrm{T}_{8}$ & 1 & $0-3$ & 2 & $0-3$ & $0,004^{* *}$ \\
\hline $\mathrm{T}_{12}$ & 1 & $0-5$ & 2 & $0-4$ & $0,042^{* *}$ \\
\hline $\mathrm{T}_{16}$ & 1 & $0-4$ & 2 & $0-3$ & 0,173 \\
\hline $\mathrm{T}_{20}$ & 1 & $0-2$ & 2 & $1-4$ & $0,002^{* *}$ \\
\hline $\mathrm{T}_{24}$ & 1 & $1-3$ & 2 & $0-3$ & 0,051 \\
\hline
\end{tabular}

Keterangan: T0=saat masuk RR, T1=1 jam, T2= jam ke-2, dan seterusnya. Nilai p dihitung berdasarkan Uji Mann Whitney. Nilai p bermakna jika $\mathrm{p}<0,05$

0-3, hal ini membuktikan bahwa kedua obat mempunyai efek analgesia yang baik untuk nyeri saat berbaring.

Gambaran penting yang didapatkan dari gabapentin dan pregabalin adalah efek kedua obat ini terhadap nyeri saat mobilisasi, yang dihubungkan dengan proses penyembuhan pascaoperatif. ${ }^{7}$ Penilaian NRS saat mobilisasi (NRS 1) pada kelompok gabapentin $600 \mathrm{mg}$ dan juga pregabalin 150 mg mempunyai nilai $\mathrm{p}<0,05$ pada 7 dari sepuluh waktu pengukuran. Hasil ini berhasil membuktikan bahwa secara statistika, pregabalin $150 \mathrm{mg}$ dengan profil farmakokinetik yang lebih unggul ternyata memang lebih baik bila dibandingkan dengan gabapentin $600 \mathrm{mg}$.

Pada hasil penilaian NRS saat berbaring, (NRS 0) tidak didapatkan pemberian petidin tambahan, sedangkan pada NRS saat mobilisasi (NRS 1) didapat pemakaian analgetik petidin tambahan, yaitu pada kelompok gabapentin 600 mg didapatkan 3 kali dan pregabalin 150 mg ada 2 kali pemberian. Bila dilihat, jumlah pemakaian petidin tambahan pregabalin lebih sedikit bila dibandingkan dengan gabapentin, akan tetapi secara statistika tidak didapatkan perbedaan bermakna antara kedua kelompok $(\mathrm{p}>0,05)$.

Perbedaan hasil dari penelitian ini diduga disebabkan oleh regimen dosis gabapentin dan

Tabel 5 Perbandingan Pemakaian Analgetik Tambahan antara Kelompok Gabapentin 600 mg dan Pregabalin $150 \mathrm{mg}$

\begin{tabular}{lccc}
\hline \multirow{2}{*}{ Variabel } & \multicolumn{2}{c}{ Kelompok } & \multirow{2}{*}{ Nilai p } \\
\cline { 2 - 3 } & PG (n=22) & GB (n=22) & \\
\hline $\begin{array}{l}\text { Tanpa tambahan } \\
\text { analgetik }\end{array}$ & 20 & 19 & 0,119 \\
$\begin{array}{l}\text { Dengan tambahan } \\
\text { analgetik }\end{array}$ & 2 & 3 & \\
\hline
\end{tabular}

Keterangan: nilai p dihitung berdasarkan Uji Mann-Whitney. Nilai p bermakna jika $p<0,05$ 
Tabel 6 Perbandingan Waktu Pemberian Analgetik Tambahan yang Pertama antara Kelompok Gabapentin $600 \mathrm{mg}$ dan Pregabalin $150 \mathrm{mg}$

\begin{tabular}{|c|c|c|c|c|}
\hline Kelompok & $\begin{array}{c}\text { Interval Waktu NRS Saat } \\
\text { Diam (Jam) }\end{array}$ & Nilai p & $\begin{array}{c}\text { Interval Waktu NRS } \\
\text { Saat Mobilisasi } \\
\text { (Jam) }\end{array}$ & Nilai p \\
\hline $\begin{array}{l}\text { PG } 150 \\
M e a n \pm S D\end{array}$ & - & \multirow[b]{2}{*}{0,317} & $1,81 \pm 6,01$ & \multirow[b]{2}{*}{0,043} \\
\hline $\begin{array}{l}\mathrm{GB} 600 \\
\text { Mean } \pm \mathrm{SD}\end{array}$ & $0,1364 \pm 0,6396$ & & $1,77 \pm 2,65$ & \\
\hline
\end{tabular}

Keterangan: nilai p dihitung berdasarkan Uji Mann-Whitney. Nilai p bermakna jika $p<0,05$

pregabalin antara penelitian ini dan penelitian sebelumnya yang berbeda, karena pemberian dosis yang berbeda dapat menimbulkan efek yang juga berbeda.

Jenis analgetik opioid yang dipergunakan pada penelitian sebelum ini adalah tramadol, sedangkan pada penelitianini mempergunakan petidin. Menurut tangga analgesia dari WHO, untuk penanganan nyeri yang sedang dan berat diberikan adjuvan disertai opioid (morfin atau tramadol). Penelitian ini menggunakan petidin sebagai analgetik opioid yang setara dengan morfin dalam perbandingan $10 \mathrm{mg}$ morfin setara dengan 75-100 mg petidin. Tramadol $100 \mathrm{mg}$ setara efektivitasnya dengan petidin $75 \mathrm{mg}$ untuk nyeri persalinan, tetapi petidin akan lebih baik menangani nyeri pascaoperatif pada dosis yang sama dibandingkan dengan tramadol.

Kejadian efek samping akibat pemberian pregabalin yang sering dilaporkan di antaranya ialah somnolen, pusing, mulut kering, edema perifer, mata kabur, peningkatan berat badan, dan gangguan konsentrasi. ${ }^{9}$ Pada penelitian ini didapatkan efek samping pregabalin $150 \mathrm{mg}$ adalah mengantuk, mual, pusing, dan muntah.

Gabapentin serta pregabalin mempunyai efek mengantuk, tetapi opioid juga. Efek mual yang terjadi pada penelitian ini tidak hanya disebabkan oleh gabapentin serta pregabalin, tetapi juga disebabkan karena trauma operasi pada penelitian ini.

Insiden efek samping yang ditemukan pada kelompok gabapentin $600 \mathrm{mg}$ dan pregabalin $150 \mathrm{mg}$ adalah sama (tidak bermakna).

\section{Simpulan}

Pemberian pregabalin $150 \mathrm{mg}$ preoperatif mempunyai nilai NRS lebih kecil dibandingkan dengan gabapentin $600 \mathrm{mg}$ pada pembedahan modifikasi radikal mastektomi dan juga jumlah kebutuhan opioid pascaoperatif yang sama.

\section{Daftar Pustaka}

1. Couceiro TCM, Menezes TC, Valenca MM. Post-mastectomy pain syndrome. The magnitude of the problem. Rev Bras Anestesiol. 2009;59(3):358-65.

2. Tiippana EM, Hamunen K, Kontinen VK, Kalso E. Do surgical patients benefit from perioperative gabapentin/pregabalin? A systematic review of efficacy and safety. Anesth Analg. 2007;104:1545-56.

3. Tzellos TG, Papazisis G, Amaniti E, Kouvelas D. Efficacy of pregabalin and gabapentin for neuropathic pain in spinalcord injury: an evidence-based evaluation of the literature. Eur J Clin Pharmacol. 2008;64:851-8.

4. Pandey CK1, Navkar DV, Giri PJ, Raza M, Behari S, Singh RB, dkk. Eveluation of the optimal preemptive dose of gabapeatin for postoperative pain relief after lumbar discectomy: a randomized, double-blind, placebo-controlled study. J Neurosurg Anesthesiol. 2005;17:65-8.

5. Zhang J, Ho KY, Wang Y. Efficacy of pregabalin in acute postoperative pain: a meta-analysis. $\mathrm{Br} \mathrm{J}$ Anaesth. 2011;106(4):454-62. 
6. Ozgencil E, Yalcin S, Tuna H, Yorukoglu D, Kecik Y. Perioperative administration of gabapentin $1.200 \mathrm{mg}^{\text {day }^{-1}}$ and pregabalin $300 \mathrm{mg} \mathrm{day}^{-1}$ for pain following lumbar laminectomy and discectomy: a randomised, double-blinded, placebocontrolled study. Singapore Med J. 2011;52(12):883-9.

7. Gilron I. Gabapentin and pregabalin for chronic neuropathic and early postsurgical pain: current evidence and future direction. Curr Opin Anesthesiol. 2007;20:456-72.

8. Kong VKF, Irwin MG. Gabapentin: amultimodal perioperative drug? BJA. 2007;99:775-86.

9. Gajraj MN. Pregabalin: its pharmacology and use in pain management. Anaesth Analg. 2007;105:1805-15. 